\title{
Uso de Antibiótico, de Probiótico e de Homeopatia, em Frangos de Corte Criados em Ambiente de Conforto, Inoculados ou não com Escherichia coli, ${ }^{1}$
}

\author{
Adriano José Boratto ${ }^{2}$, Darci Clementino Lopes ${ }^{3}$, Rita Flávia Miranda de Oliveira ${ }^{3}$, \\ Luiz Fernando Teixeira Albino ${ }^{3}$, Luciano Moraes Sá ${ }^{4}$, Gisele Andrade de Oliveira ${ }^{5}$
}

\begin{abstract}
RESUMO - Para avaliar o efeito do uso de antibiótico, de probiótico e de homeopatia em frangos de corte, inoculados ou não com Escherichia coli, foram distribuídos 672 frangos machos, Avian Farm, em delineamento inteiramente casualizado em esquema fatorial com oito tratamentos (quatro aditivos x com ou sem inoculação) e seis repetições, tendo 14, 12 e 7 aves por unidade experimental, respectivamente, de acordo com os períodos 1 a 11, 12 a 21 e 22 a 42 dias de idade. As aves foram alojadas em salas climatizadas em ambiente de conforto, de acordo com o manual da linhagem. Os tratamentos foram constituídos de: controle negativo (sem aditivo), antibiótico (virginiamicina + nitrovin), probiótico (meio de cultura de Lactobacilus acidophillus, Enterococcus faecium e Saccharomices cerevisiae) e homeopatia (nosódio de Escherichia coli). Observou-se que as aves tratadas com antibiótico e probiótico apresentaram maior ganho de peso no período de 1 a 21 dias, com melhor conversão alimentar para aquelas tratadas com antibiótico, embora no período total de 1 a 42 dias não tenha havido diferença entre os tratamentos. A inoculação da Escherichia coli piorou o desempenho das aves, aumentando o peso relativo do coração, do fígado e dos intestinos, enquanto o uso de antibiótico e de probiótico melhorou o desempenho das aves no período de 1 a 21 dias.
\end{abstract}

Palavras-chave: ambiente, Escherichia coli, frango de corte, promotor de crescimento

\section{Use of Antibiotic, Probiotic and Homeopathy, Inoculated or not with Escherichia coli, for Broilers Reared under Comfort Environment}

\begin{abstract}
The effect of antibiotic, probiotic and homeopathy in broilers inoculated or not with Escherichia coli was evaluated. Six hundred and seventy two male broilers of Avian Farm strain were assigned to a completely randomized design, in a factorial scheme, with eight treatments (four additives x inoculation or not) and six replicates, with 14, 12 and 7 birds by experimental box, respectively, according to the periods from 1 to 11 , from 12 to 21 and from 22 to 42 days of age. The birds were allotted to acclimatized chambers, under comfort environment, according to the strain recommendations. The treatments were constituted of: negative control (no additive), antibiotic (virginiamicine + nitrovin), probiotic (culture medium of Lactobacilus acidophillus, Enterococcus faecium and Saccharomices cerevisiae) and homeopathy (nosody of Escherichia coli). It was observed that birds fed antibiotic and probiotic showed higher weight gain from 1 to 21 days, and the birds fed antibiotic showed the best feed:gain ratio, although in the total period (from 1 to 42 days of age) there was no difference among treatments. The inoculation with Escherichia coli decreased the birds performance; the bacteria increased the relative weight of heart, liver and intestines. It was concluded that the use of antibiotic and probiotic improved the birds performance from 1 to 21 days of age.
\end{abstract}

Key Words: broiler chicks, enviroment, Escherichia coli, performance promoter

\section{Introdução}

A contaminação microbiológica do ambiente em que são criados pode exercer pressão sobre a saúde e o desempenho produtivo dos animais. Se as condições de criação e manejo forem adequadas, é provável que não exista efeito significativo dos aditivos promotores de crescimento no desempenho das aves. Diferentes respostas podem ser encontradas em testes realizados a campo e em estações experimentais, segundo as distintas condições de criação.

A manutenção do ambiente de conforto térmico e o controle dos níveis de contaminação nas dietas, instalações e nos equipamentos não são totalmente controlados dentro das unidades produtivas, pois desvios das situações ideais de manejo são comuns e

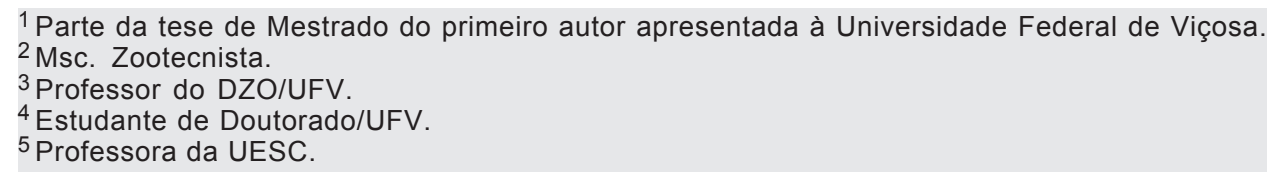


provocam problemas técnicos de difícil solução. A individualidade de cada criação e o dinamismo do processo devem ser considerados, pois seguir uma única indicação na administração dos aditivos nas rações pode levar a erros. É um grande desafio conciliar as diversas variáveis, satisfazendo plenamente todos requisitos de uma criação, tornando, muitas vezes, a utilização dos promotores indispensável. Assim, estudar respostas dos aditivos sob diferentes situações ambientais auxilia na adoção de alternativas e procedimentos adequados que indiquem a possibilidade de criar animais sem a utilização de quaisquer aditivos que, porventura, possam trazer prejuízos à saúde animal e humana.

Este estudo foi realizado para avaliar os efeitos do uso de antibiótico, de probiótico e de homeopatia sobre o desempenho produtivo e desenvolvimento de órgãos de frangos de corte de 1 a 42 dias, criados em ambiente térmico de conforto, desafiados ou não por meio da inoculação de Escherichia coli.

\section{Material e Métodos}

O experimento foi conduzido no Laboratório de Bioclimatologia Animal do Departamento de Zootecnia do Centro de Ciências Agrárias da Universidade Federal de Viçosa, em Viçosa-MG.

Foram alojados, em salas climatizadas, 672 pintos de corte da linhagem Avian Farms com um dia de vida. O delineamento experimental foi o inteiramente casualizado em esquema fatorial $4 \times 2$ (quatro aditivos $\mathrm{x}$ com ou sem inoculação), totalizando oito tratamentos, com seis repetições, cada um contendo 14, 12 e 7 aves por unidade experimental, respectivamente, de acordo com os períodos experimentais de 1 a 11 , de 12 a 21 e de 22 a 42 dias de idade. As aves foram distribuídas segundo o peso médio padrão do lote e, ao iniciar cada um dos períodos experimentais, foram alojadas nas salas climatizadas em baterias metálicas, em um compartimento de $0,72 \mathrm{~m}^{2}$, constituído de piso de arame, e provido de comedouro e bebedouro tipo calha.

As inoculações foram feitas via água de beber com, em média, $7 \mathrm{~mL}$ de caldo/ave/dia, contendo $10^{8} \mathrm{UFC} / \mathrm{mL}$ da bactéria $E$. coli, fornecido do $4^{\circ}$ ao $10^{\mathrm{O}} \mathrm{dia}$, sendo que, do $26^{\circ} \mathrm{O}$ ao $28^{\circ}$, foram colocados $14 \mathrm{~mL}$ do caldo. O preparo do caldo se deu pela mistura de cinco amostras de E. coli, isoladas de fígado de aves com colibacilose. As bactérias liofilizadas foram reativadas e, por meio de plaqueamento das cepas, incubação e multiplicação, em fotofotômetro, realizou-se a leitura da densidade ótica do meio, para que houvesse padronização do número de células inoculadas. A multiplicação das bactérias foi realizada em meio $\mathrm{BHI}$ a $37^{\circ} \mathrm{C}$, por 24 horas.

O ambiente interno das salas foi monitorado diariamente em dois horários ( 8 e $18 \mathrm{~h}$ ); a temperatura e a umidade relativa do ar foram medidas por meio de termômetros (bulbo seco, bulbo úmido e globo negro). Constam, na Tabela 1, as condições ambientais (conforto e frio) a que as aves foram submetidas durante o período experimental.

Duas rações (Tabela 2) foram formuladas para os períodos de 1 a 21 e 22 a 42 dias de idade, para satisfazer as exigências nutricionais dos frangos de corte, segundo Rostagno et al. (2000). Durante o período experimental, as aves receberam ração e água à vontade, sendo a água trocada duas vezes ao dia.

O programa de luz foi contínuo (24 horas de luz artificial), utilizando-se lâmpadas fluorescentes, totalizando 75 watts por sala durante todo o período experimental.

Os tratamentos foram constituídos de:

1 - Antibiótico: combinação de virginiamicina e nitrovin com níveis de inclusão de 10 e 25 ppm, respectivamente, adicionados nas rações 1 e 2 , e oferecido em todo período experimental ( 1 a 42 dias);

Tabela 1 - Valores médios de temperatura e umidade relativa, observados nas salas climáticas no período de 1 a 11,12 a 21 e 22 a 42 dias de idade

Table 1 - Average values of temperature and relative humidity in the climatic rooms from 1 to 11 , from 12 to 21 and from 22 to 42 days of age

\begin{tabular}{ccc}
\hline $\begin{array}{c}\text { Idade (dias) } \\
\text { Age (days) }\end{array}$ & $\begin{array}{c}\text { Temperatura } \\
\text { do ar }\left({ }^{\circ} \mathrm{C}\right)\end{array}$ & $\begin{array}{c}\text { Umidade } \\
\text { relativa }(\%) \\
\text { Air temperature }\left({ }^{\circ} \mathrm{C}\right)\end{array}$ \\
$\begin{array}{ccc}\text { Relative humidity }(\%) \\
1\end{array}$ & 33 & 68 \\
2 & 32 & 65 \\
3 & 31 & 66 \\
4 & 31 & 67 \\
5 & 29 & 70 \\
6 & 29 & 68 \\
7 & 29 & 69 \\
8 & 29 & 69 \\
9 & 29 & 71 \\
10 & 29 & 71 \\
11 & 29 & 72 \\
12 a 21 & 28 & 76 \\
21 a 42 & 25 & 74 \\
\hline
\end{tabular}


Tabela 2 - Composição percentual das rações experimentais dos períodos de 1 a 21 dias e 22 a 42 dias de idade

Table 2 - Composition of the experimental diets (\%) from 1 to 21 and from 22 to 42 days of age

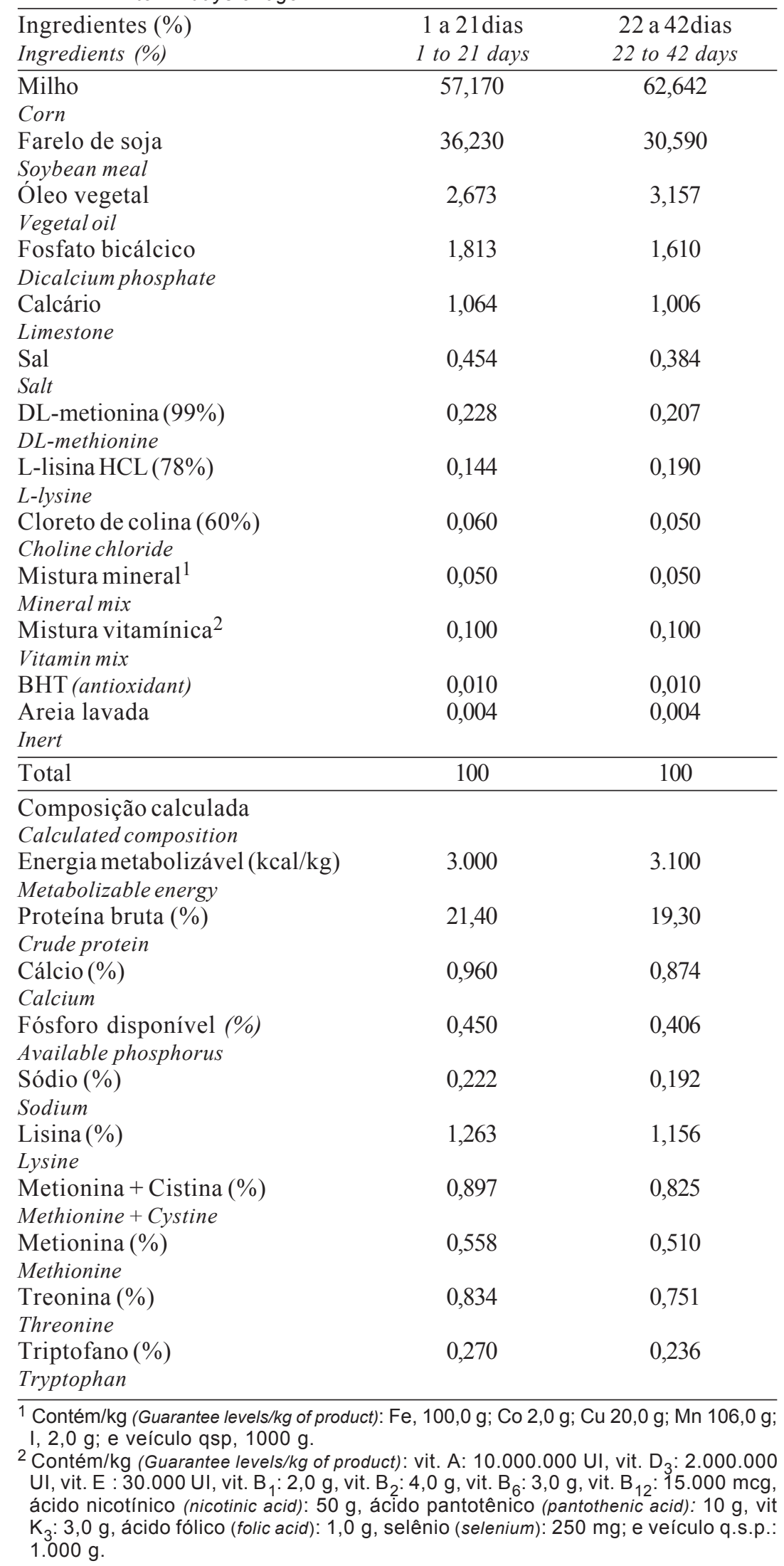


2 - Probiótico: (meio de cultura de Lactobacilus acidophilus, Enterococcus faecium e Sacaromices cerevisiae) administrado na água de beber sob diluição de 1:100. Oferecido em todo período experimental (1 a 42 dias);

3 - Homeopatia: (nosódio de E. coli com dinamização $\mathrm{CH} 30$ ), colocado na água de beber na diluição de 1:1000. Oferecido em todo período experimental (1 a 42 dias); e

4 - Controle: ração basal isenta de aditivo promotor de crescimento. Oferecida em todo o período experimental ( 1 a 42 dias).

As aves foram pesadas no início e no final de cada período experimental, visando determinação do ganho de peso. No cálculo do consumo de ração, consideraram-se a ração fornecida, os desperdícios e as sobras nos comedouros, ocorridos durante o período experimental e, posteriormente, calculou-se a conversão alimentar.

No final de cada período experimental (11으 $21^{\circ}$ e 42을a), após 12 horas de jejum, foram selecionadas duas aves representantes do peso médio de cada boxe e as abatidas por meio de deslocamento cervical.

As carcaças, sem sangue, penas e vísceras, foram pesadas em balança de $1 \mathrm{~g}$. Coração e fígado foram retirados e pendurados de modo que o sangue escorresse, o intestino foi limpo, retirando todo o conteúdo da digesta presente em seu lúmen e, após tais procedimentos, os órgãos foram pesados em balança de $0,02 \mathrm{~g}$.

O peso relativo dos órgãos foi calculado em relação ao peso em jejum (aos 11 dias) em relação à carcaça eviscerada e sem penas, no $21^{\circ} \underline{\mathrm{O}}$ e $42^{\mathrm{o}} \underline{\mathrm{o}}$ dia de idade das aves.

Foram avaliados o ganho de peso, o consumo de ração, a conversão alimentar, o peso $(\mathrm{g})$ e rendimento (\%) das carcaças inteiras (com pés e cabeça) e os pesos absoluto (g) e relativo (\%) do coração, dos intestinos e do fígado.

Os intestinos das aves abatidas aos 11 dias foram medidos e, na metade do seu comprimento, foi retirado um corte de $1,0 \mathrm{~cm}$. Os fragmentos foram imediatamente lavados em solução fisiológica, fixados em BOUIN por 24 horas, desidratados em álcool, diafanizados, impregnados em xilol e incluídos em parafina. Com micrótomo, realizaram-se seções com $4 \mu \mathrm{m}$ de espessura. O método de coloração adotado foi o hematoxilina-eosina. As lâminas histológicas foram preparadas de acordo com Behmer \& Tolosa (1976).
As análises morfométricas dos cortes histológicos foram realizadas no Laboratório de Nutrição Animal do Departamento de Zootecnia da Universidade Federal de Viçosa, usando o microscópio Olympus BX50, focado no aumento de 40 vezes e acoplado a um programa analisador de imagem. Para cada ave, foram montadas duas lâminas e, em cada uma, foram realizadas 30 medições, a partir das quais foram realizadas médias da altura de vilosidades, da profundidade das criptas e da espessura da túnica muscular.

As análises estatísticas das variáveis (ganho de peso, conversão alimentar e consumo de ração, peso de órgão e morfometria intestinal) foram realizadas utilizando-se o programa SAEG (Sistema para Análises Estatísticas e Genéticas), UFV (1992).

\section{Resultados e discussão}

Os valores médios de ganho de peso (GP), de consumo de ração (CR) e de conversão alimentar (CA) de frangos de corte tratados com antibiótico, probiótico e homeopatia, nos períodos de 1 a 11 , 12 a 21,1 a 21,22 a 42 e 1 a 42 dias de idade, encontram-se na Tabela 3 .

A interação tratamentos $\mathrm{x}$ inoculação não foi significativa $(\mathrm{P}>0,05)$ para nenhum dos parâmetros analisados. Houve efeito $(\mathrm{P}<0,05)$ dos tratamentos sobre o ganho de peso, o consumo de ração e a conversão alimentar.

No período de 1 a 11 dias, as aves tratadas com probiótico apresentaram maior GP que aquelas do tratamento-controle, porém semelhante às dos tratamentos antibiótico e homeopatia. Nos períodos de 12 a 21 e 1 a 21 dias, os tratamentos antibiótico e probiótico aumentaram o GP em relação aos tratamentos controle e homeopatia; nos demais períodos, não houve efeito dos tratamentos sobre o GP.

Nos períodos de 12 a 21 dias e de 1 a 21 dias, o CR das aves tratadas com probiótico foi maior que o CR daquelas submetidas aos tratamentos controle e homeopatia e semelhante ao das aves tratadas com antibiótico. Nesses períodos, verificou-se que as aves tratadas com antibiótico apresentaram a melhor CA.

Nos demais períodos, o desempenho das aves não foi alterado pelos tratamentos, resultados que se aproximam da citação de Silva (2000), em que os promotores de crescimento melhoraram o ganho de peso e a conversão alimentar, principalmente nas fases iniciais da criação. Zuanon (1995), estudando o uso de antibióticos e/ou probiótico em aves criadas no 


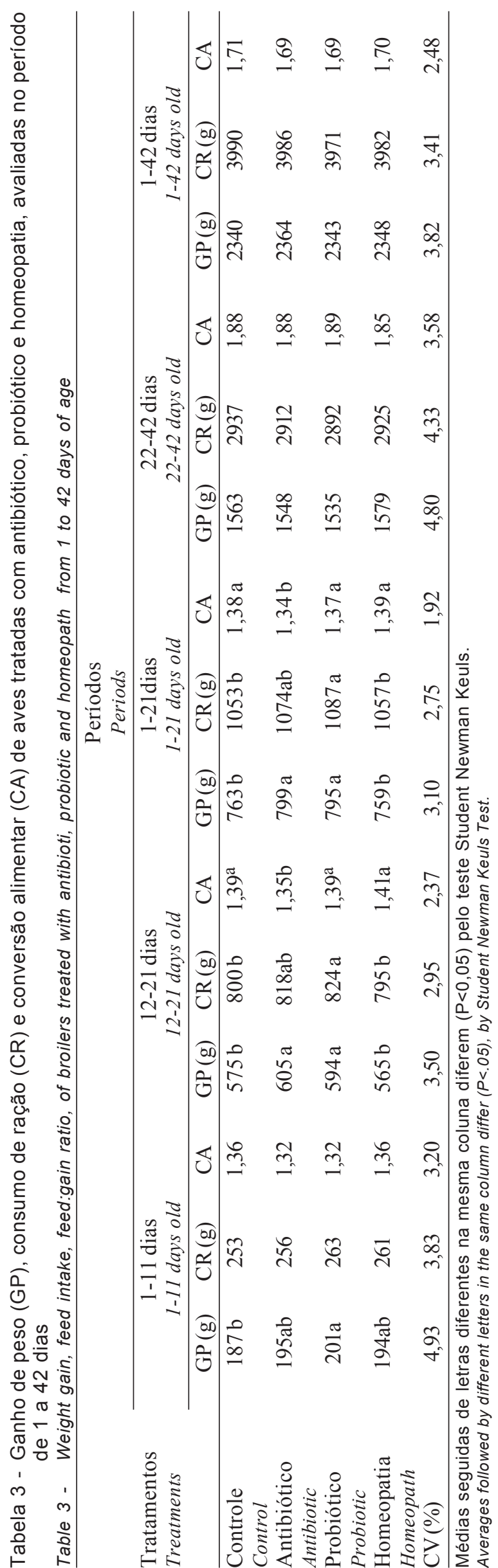

chão, portanto com certa contaminação microbiológica, encontrou diferenças significativas no desempenho de frangos de corte no período de 1 a 21 dias de idade e não observou estas diferenças ao final do período experimental.

É difícil comparar os resultados de estudos científicos conduzidos com aditivos, uma vez que cada trabalho utiliza determinado tipo de promotor de crescimento, com diferentes dosagens e formas de administração e em condições experimentais distintas. Freitas (1992), estudando diferentes níveis de alho na ração e os efeitos de diferentes níveis de promotores de crescimento em aves criadas em baterias metálicas, concluiu que, devido às boas condições de criação, não foram observadas diferenças significativas entre os promotores utilizados na alimentação das aves. Henrique et al. (1998) e Loddi et al. (1998), avaliando o desempenho de frangos de corte, não observaram efeito da adição de antibióticos na ração de frangos de corte, e atribuíram a falta de expressão da eficiência dos mesmos ao fato de os animais avaliados terem sido criados em instalações novas com ótimas condições profiláticas.

Os resultados de desempenho indicam que o desafio que aves sofreram com inoculação de E. coli não foi suficientemente intenso para provocar uma resposta mais efetiva dos aditivos, sobretudo no período de 22 a 42 dias de idade, e que o fato de as aves terem sido alojadas em baterias metálicas contribuiu para que estas ficassem isoladas do contato com as fezes. Um estudo com frangos sob as mesmas condições, porém criados em cama, provavelmente apresentaria resultados diferentes com relação à contaminação do ambiente e das aves, pois, em cada grama de fezes, pode haver cerca de $10^{6}$ UFC de E. coli, das quais se estima que $15 \%$ podem ser patogênicas para pintos de um dia, que, à medida que crescem adquirem a resistência contra esse microrganismo.

Deve-se considerar que a $E$. coli é incapaz de produzir doença clínica acima de 3\% nos plantéis, exceto em interações com outros agentes. Trabalhos com inoculações têm mostrado que a virulência desta bactéria está associada a outros microrganismos e que os animais inoculados apenas com E. coli apresentaram sintomas discretos, com menos lesões e menor persistência, quando comparados com inoculações associadas. Existem controvérsias sobre a colibacilose e a população da E. coli no intestino, seu equilíbrio com a microbiota, e o papel desta na imunidade Guimarães (1993). 
Apesar de não ter havido interação tratamento $\mathrm{x}$ ambiente inoculado e não-inoculado, houve efeito $(\mathrm{P}<0,05)$ da inoculação da $E$. coli sobre o consumo de ração, o GP e a CA das aves inoculadas (Tabela 4). Observou-se que, no período de 1 a 11 dias de idade, as aves inoculadas reduziram o GP em $16 \%$ e o CR em $7 \%$, sendo que a CA desses animais foi pior (9\%) em comparação às aves não-inoculadas. No período de 1 a 21 dias de idade, o desempenho continuou com respostas semelhantes, mas refletidas em percentual menor, sendo que as aves inoculadas reduziram o GP em $2 \%$ e o CR em $5 \%$ e apresentaram CA $2 \%$ pior em relação aos animais não-inoculados. Ao final do período de 1 a 42 dias, o CR e o GP foi $2 \%$ menor para as aves inoculadas, sendo que a CA foi semelhante $(\mathrm{P}>0,05)$ à das aves não-inoculadas.

No período de 12 a 21 dias, ou seja, após a primeira inoculação, não houve efeito da inoculação sobre os parâmetros avaliados. A segunda inoculação não influenciou $(\mathrm{P}>0,05)$ o desempenho das aves no período de 22 a 42 dias. Os animais neonatos são mais susceptíveis às enfermidades, pois nascem com uma população de anticorpos limitada a doenças a que as matrizes foram imunizadas, não havendo anticorpos para vários agentes causadores de problemas entéricos.

Após o nascimento, começa a ser desenvolvida a população microbiana da ave, que vai da cavidade bucal ao ceco e evolui gradativamente durante as primeiras semanas de vida. Segundo Jorge (1990), contagens de E. coli realizadas em cama de frango apresentam os maiores valores entre 20 e 30 dias de idade das aves, o que talvez possa justificar o efeito significativo da inoculação da bactéria apenas na fase inicial, além do número de bactérias e da distribuição das administrações nas duas inoculações.

Os valores médios dos pesos absoluto e relativo dos órgãos (coração, fígado e intestinos) dos frangos de corte, nas idades de 11, 21 e 42 dias da idade, encontram-se nas Tabelas 5 e 6 .

Não houve interação tratamento $\mathrm{x}$ ambiente inoculado e não-inoculado para nenhum dos parâmetros avaliados. Não houve efeito $(\mathrm{P}>0,05)$ de tratamento sobre os pesos absoluto e relativo dos órgãos avaliados. O peso absoluto dos órgãos não foi influenciado $(\mathrm{P}>0,05)$ pela inoculação, à exceção do peso absoluto do coração aos 11 dias.

A inoculação influenciou $(\mathrm{P}<0,05)$ os pesos relativos do coração (PRC), do fígado (PRF) e do intestino (PRI), nas três idades analisadas. As aves inoculadas

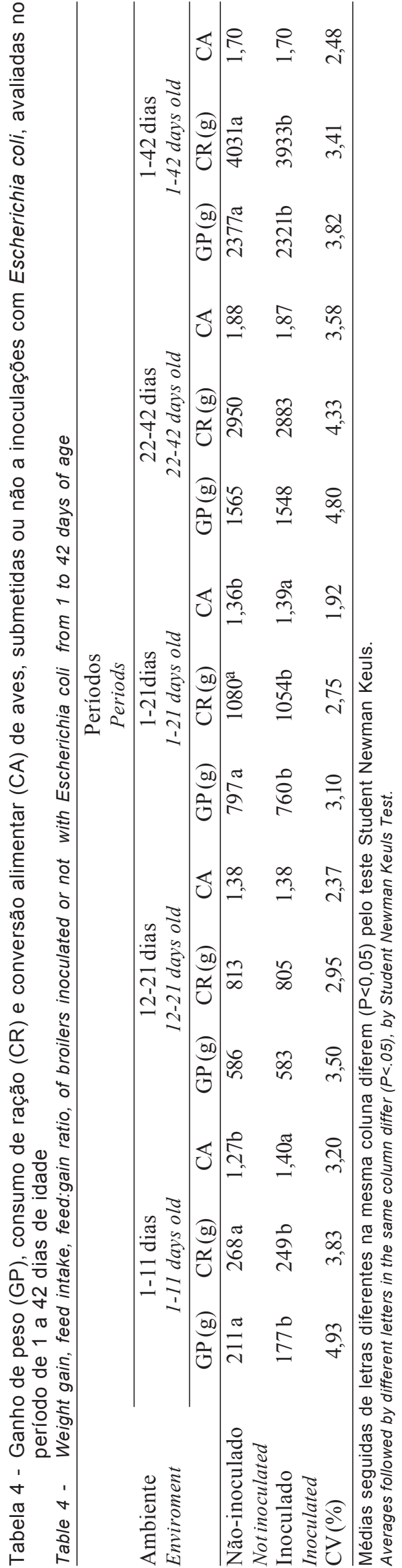


apresentaram o PRF e o PRI aumentado aos 11 dias, sendo que aos 21 dias as aves inoculadas tiveram o peso relativo elevado para os três órgãos avaliados. Nota-se que, aos 42 dias, estes valores permaneceram superiores para PRC e para PRF e semelhante $(\mathrm{P}>0,05)$ para PRI.

Nitsan et al. (1991) verificaram que, durante os 23 primeiros dias de idade, o crescimento alométrico do intestino de aves foi quatro vezes maior e do fígado, aproximadamente duas vezes maior que a carcaça total da ave. Segundo Merck (1991), a resposta clínica à infecção por $E$. coli depende da localização e do grau de infecção. A aerossaculite associada ou não à pericardite, peri-hepatite e peritonite são os sinais mais comuns, mas infecções agudas e sistêmicas, como enterite, inflamação e aumento de volume dos órgãos parenquimatosos podem ser uma expressão típica. O fígado foi o único órgão afetado nas três fases estudadas, o que pode estar relacionado à neutralização de substâncias tóxicas produzidas a partir da atividade metabólica das bactérias intestinais, que requer um gasto constante da energia para desintoxicação feita pelo fígado, induzindo uma hipertrofia dos hepatócitos.
A mucosa intestinal é responsável pela absorção dos alimentos, que é feita nas vilosidades através dos enterócitos. O número desses enterócitos está associado ao tamanho dos vilos e seu aumento reflete em maior absorção do alimento. Os enterócitos do intestino delgado apresentam polissacarídeos denominados glicocalix; a colonização por bactérias nos diferentes segmentos do intestino parece estar na dependência da aderência do glicocalix de uma bactéria com o glicocalix do enterócito Macari et al. (2000).

Os valores médios de altura do vilo, profundidade da cripta, relação vilo/cripta e túnica muscular, em função do uso de antibiótico, de probiótico e de homeopatia, bem como da inoculação ou não da $E$. coli, encontram-se na Tabela 7.

Não houve interação tratamento $\mathrm{x}$ inoculação para nenhum dos parâmetros avaliados. Não se observou influência $(\mathrm{P}>0,05)$ dos tratamentos em nenhuma das mensurações intestinais realizadas. A inoculação diminuiu a altura do vilo, em termos absolutos, aumentou a profundidade da cripta $(\mathrm{P}<0,05)$ e reduziu a relação vilo/cripta.

Tabela 5 - Resultados de pesos absoluto $(\mathrm{g})$ de órgãos de frangos de corte em três idades, alimentados com diferentes aditivos e criados com ou sem inoculação com Escherichia coli

Table 5 - Absolute weight $(g)$ of broiler chicks organs in three different ages, treated with different additives and inoculated or not with Escherichia coli

\begin{tabular}{|c|c|c|c|c|c|c|c|c|c|}
\hline \multirow{4}{*}{$\begin{array}{l}\text { Tratamentos } \\
\text { Treatments }\end{array}$} & \multicolumn{9}{|c|}{$\begin{array}{c}\text { Idade das aves } \\
\text { Chicks age }\end{array}$} \\
\hline & \multicolumn{3}{|c|}{$\begin{array}{l}11 \text { dias } \\
11 \text { days old }\end{array}$} & \multicolumn{3}{|c|}{21 dias } & \multicolumn{3}{|c|}{$\begin{array}{c}42 \text { dias } \\
42 \text { davs old }\end{array}$} \\
\hline & \multicolumn{3}{|c|}{$\begin{array}{c}\text { Peso absoluto }(\mathrm{g}) \\
\text { Absolute weight }\end{array}$} & \multicolumn{3}{|c|}{$\begin{array}{c}\text { Peso absoluto }(\mathrm{g}) \\
\text { Absolute weight }\end{array}$} & \multicolumn{3}{|c|}{$\begin{array}{c}\text { Peso absoluto }(\mathrm{g}) \\
\text { Absolute weight }\end{array}$} \\
\hline & $\begin{array}{c}\text { Coração } \\
\text { Heart }\end{array}$ & $\begin{array}{c}\text { Fígado } \\
\text { Liver }\end{array}$ & $\begin{array}{c}\text { Intestino } \\
\text { Intestine }\end{array}$ & $\begin{array}{c}\text { Coração } \\
\text { Heart }\end{array}$ & $\begin{array}{c}\text { Fígado } \\
\text { Liver }\end{array}$ & $\begin{array}{c}\text { Intestino } \\
\text { Intestine }\end{array}$ & $\begin{array}{c}\text { Coração } \\
\text { Heart }\end{array}$ & $\begin{array}{c}\text { Fígado } \\
\text { Liver }\end{array}$ & $\begin{array}{c}\text { Intestino } \\
\text { Intestine }\end{array}$ \\
\hline $\begin{array}{l}\text { Controle } \\
\text { Control }\end{array}$ & 1,73 & 6,58 & 14,49 & 5,01 & 17,94 & 25,53 & 11,46 & 39,43 & 54,50 \\
\hline $\begin{array}{l}\text { Antibiótico } \\
\text { Antibiotic }\end{array}$ & 1,76 & 7,02 & 15,01 & 5,24 & 18,23 & 25,43 & 11,58 & 41,40 & 52,52 \\
\hline $\begin{array}{l}\text { Probiótico } \\
\text { Probiotic }\end{array}$ & 1,75 & 7,17 & 15,71 & 4,88 & 17,66 & 26,23 & 11,29 & 41,05 & 52,57 \\
\hline $\begin{array}{l}\text { Homeopatia } \\
\text { Homeopath } \\
\text { Ambiente }\end{array}$ & 1,81 & 7,18 & 15,95 & 4,88 & 17,74 & 26,51 & 12,05 & 41,08 & 54,25 \\
\hline $\begin{array}{l}\text { Enviroment } \\
\text { Não-inoculado } \\
\text { Notinoculated }\end{array}$ & $1,86 \mathrm{a}$ & 7,07 & 15,58 & 4,95 & 17,70 & 24,95 & 11,37 & 39,40 & 54,38 \\
\hline $\begin{array}{l}\text { Inoculado } \\
\text { Inoculated }\end{array}$ & $1,66 \mathrm{~b}$ & 6,90 & 14,99 & 5,05 & 18,07 & 26,89 & 11,82 & 42,08 & 52,55 \\
\hline CV $(\%)$ & 9,07 & 9,01 & 8,3 & 12,41 & 11,20 & 13,74 & 10,41 & 12,96 & 8,10 \\
\hline
\end{tabular}

Médias seguidas de letras diferentes na mesma coluna diferem $(P<0,05)$ pelo teste Student Newman Keuls.

Averages followed by different letters in the same column differ $(P<.05)$, by Student Newman Keuls Test.

R. Bras. Zootec., v.33, n.6, p.1477-1485, 2004 
Tabela 6 - Resultados de peso relativo (\%) de órgãos de frangos de corte em três idades, alimentados com diferentes aditivos e criados com ou sem inoculação com Escherichia coli

Table 6 - Relative weight $(g)$ of broiler chicks organs in three different ages, treated with different additives and inoculated or not with Escherichia coli

\begin{tabular}{|c|c|c|c|c|c|c|c|c|c|}
\hline \multirow{5}{*}{$\begin{array}{l}\text { Tratamentos } \\
\text { Treatments }\end{array}$} & \multicolumn{9}{|c|}{$\begin{array}{l}\text { Idade das aves } \\
\text { Chicks age }\end{array}$} \\
\hline & \multirow{2}{*}{\multicolumn{3}{|c|}{$\begin{array}{l}11 \text { dias } \\
11 \text { days old }\end{array}$}} & \multicolumn{3}{|c|}{21 dias } & \multirow{2}{*}{\multicolumn{3}{|c|}{$\begin{array}{c}42 \text { dias } \\
42 \text { days old }\end{array}$}} \\
\hline & & & & & 21 days olc & & & & \\
\hline & \multicolumn{3}{|c|}{$\begin{array}{c}\text { Peso relativo }(\mathrm{g}) \\
\text { Relative weight }\end{array}$} & \multicolumn{3}{|c|}{$\begin{array}{c}\text { Peso relativo (g) } \\
\text { Relative weight }\end{array}$} & \multicolumn{3}{|c|}{$\begin{array}{c}\text { Peso relativo }(\mathrm{g}) \\
\text { Relative weight }\end{array}$} \\
\hline & $\begin{array}{c}\text { Coração } \\
\text { Heart }\end{array}$ & $\begin{array}{l}\text { Fígado } \\
\text { Liver }\end{array}$ & $\begin{array}{l}\text { Intestino } \\
\text { Intestine }\end{array}$ & $\begin{array}{c}\text { Coração } \\
\text { Heart }\end{array}$ & $\begin{array}{l}\text { Fígado } \\
\text { Liver }\end{array}$ & $\begin{array}{l}\text { Intestino } \\
\text { Intestine }\end{array}$ & $\begin{array}{c}\text { Coração } \\
\text { Heart }\end{array}$ & $\begin{array}{c}\text { Fígado } \\
\text { Heart }\end{array}$ & $\begin{array}{c}\text { Intestino } \\
\text { Intestine }\end{array}$ \\
\hline $\begin{array}{l}\text { Controle } \\
\text { Control }\end{array}$ & 0,83 & 3,18 & 7,01 & 0,85 & 3,03 & 4,31 & 0,62 & 2,12 & 2,93 \\
\hline $\begin{array}{l}\text { Antibiótico } \\
\text { Antibiotic }\end{array}$ & 0,83 & 3,30 & 7,06 & 0,84 & 2,94 & 4,10 & 0,61 & 2,17 & 2,76 \\
\hline $\begin{array}{l}\text { Probiótico } \\
\text { Probiotic } \\
\text { Homeopatia } \\
\text { Homeopath } \\
\text { Ambiente } \\
\text { Environment }\end{array}$ & 0,80 & 3,31 & 7,24 & 0,85 & 3,07 & 4,57 & 0,62 & 2,25 & 2,87 \\
\hline $\begin{array}{l}\text { Não-inoculado } \\
\text { Not inoculated }\end{array}$ & 0,83 & $3,13 b$ & $6,91 \mathrm{~b}$ & $0,82 \mathrm{~b}$ & $2,93 \mathrm{~b}$ & $4,13 b$ & $0,60 \mathrm{~b}$ & $2,08 \mathrm{~b}$ & 2,88 \\
\hline $\begin{array}{l}\text { Inoculado } \\
\text { Inoculated }\end{array}$ & 0,82 & $3,42 \mathrm{a}$ & $7,44 \mathrm{a}$ & $0,86 \mathrm{a}$ & $3,08 \mathrm{a}$ & $4,60 \mathrm{a}$ & $0,64 \mathrm{a}$ & $2,29 \mathrm{a}$ & 2,86 \\
\hline
\end{tabular}

Médias seguidas de letras diferentes na mesma coluna diferem $(P<0,05)$ pelo teste Student Newman Keuls.

Averages followed by different letters in the same column differ $(P<.05)$, by Student Newman Keuls Test.

Tabela 7 - Valores médios de altura do vilo, profundidade da cripta, relação vilo/cripta, espessura de túnica muscular e porção média do intestino de pintos com 11 dias de idade tratados com antibiótico, probiótico e homeopatia, inoculados ou não com Escherichia coli

Table 7 - Avarage values of vilus height, crypt depth, vilus/crypt ratio, tunic muscle thickness and medium portion of intestin from broiler with 11 days old, treated with antibiotic, probiotic and homeopath, inoculated or not with Escherichia coli

\begin{tabular}{|c|c|c|c|c|}
\hline $\begin{array}{l}\text { Tratamentos } \\
\text { Treatments }\end{array}$ & $\begin{array}{l}\text { Altura do vilo } \\
(\mathrm{m}) \\
\text { Vilus height }\end{array}$ & $\begin{array}{l}\text { Profundidade } \\
\text { de cripta ( m) } \\
\text { Crypt depth }\end{array}$ & $\begin{array}{l}\text { Vilo/Cripta } \\
(\mathrm{m}) \\
\text { Vilus/crypt }\end{array}$ & $\begin{array}{c}\text { Túnica muscular } \\
\text { ( } \mathrm{m}) \\
\text { Tunic muscle thickness }\end{array}$ \\
\hline Controle & 654 & 145 & 4,5 & 183 \\
\hline $\begin{array}{l}\text { Control } \\
\text { Antibiótico } \\
\text { Antibiotic }\end{array}$ & 628 & 134 & 4,7 & 186 \\
\hline $\begin{array}{l}\text { Probiótico } \\
\text { Probiotic }\end{array}$ & 638 & 147 & 4,3 & 184 \\
\hline $\begin{array}{l}\text { Homeopatia } \\
\text { Homeopath } \\
\text { Ambiente } \\
\text { Enviroment }\end{array}$ & 643 & 147 & 4,4 & 182 \\
\hline $\begin{array}{l}\text { Não-inoculado } \\
\text { Not inoculated }\end{array}$ & 642 & $140 \mathrm{~b}$ & $4,6 a$ & 182 \\
\hline $\begin{array}{l}\text { Inoculado } \\
\text { Inoculated }\end{array}$ & 639 & $148 \mathrm{a}$ & $4,3 \mathrm{~b}$ & 185 \\
\hline $\mathrm{CV}(\%)$ & 5,4 & 7,4 & 6,5 & 6,1 \\
\hline
\end{tabular}

Médias seguidas de letras diferentes na mesma coluna diferem entre si, pelo teste Student Newman Keuls $(\mathrm{P}<0,05)$.

Averages followed of different letters in the same column differ signicantly $(P<.05)$, by Student Newman Keuls Test. 


\section{Conclusões}

O uso de antibiótico e de probiótico aumentaram o ganho de peso das aves no período de 1 a 21 dias da idade, sendo que as aves tratadas com antibiótico apresentaram a melhor eficiência alimentar. No período de 1 a 42 dias de idade, não se verificaram efeitos dos tratamentos sobre o desempenho.

As aves inoculadas com E. coli consumiram menos ração, apresentaram menor ganho de peso e pior conversão alimentar que as aves não-inoculadas.

A inoculação da Escherichia coli aumentou o peso relativo do coração, do fígado e do intestino das aves; a bactéria diminuiu a altura de vilos, em termos absolutos, aumentou $(\mathrm{P}<0,05)$ a profundidade da cripta e diminuiu a relação vilo/cripta.

\section{Literatura Citada}

BEHMER, O.A.; TOLOSA, E.M.C. Manual de técnicas para histologia normal e patológica. São Paulo: EDART, 1976.

FREITAS, R. O alho (Allium sativum L.) como estimulante do crescimento de frangos de corte em comparação com promotores de crescimento usados na indústria de rações. Viçosa, MG: Universidade Federal de Viçosa, 1992. 60p. Dissertação (Mestrado em Zootecnia) - Universidade Federal de Viçosa, 1992.

GUIMARÃES, I.G. Escherichia coli e suas interações em aves: patologias e métodos de controle. In: CONFERÊNCIA APINCO DE CIÊNCIA E TECNOLOGIA AVÍCOLAS, 1993, Campinas. Anais... Campinas: FACTA, 1993. p.43-71.

HENRIQUE, A.P.F.; FARIA, D.E.; FRANZOLIN R. et al. Uso de probióticos e antibióticos como promotores de crescimento para frangos de corte. In: REUNIÃO ANUAL BRASILEIRA DA SOCIEDADE BRASILEIRA DE ZOOTECNIA, 35., 1998, Botucatu. Anais... Botucatu: Sociedade Brasileira de Zootecnia, 1998. p.297-299.
JORGE, M.A. Cama de frango de corte: como fazer dela sua aliada na prevenção de enfermidades. In: CONFERÊNCIA APINCO DE CIÊNCIA E TECNOLOGIA AVÍCOLAS, 1990, Campinas. Anais... Campinas: Fundação Apinco de Ciência e Tecnologia Avícolas, 1990. p.21-28.

LODDI, M.M.; GONZALES, E.; TAKITA, R.S. et al. Efeito da adição de probiótico e antibiótico como promotores de crescimento sobre o desempenho de frangos de corte. In: REUNIÃO BRASILEIRA DA SOCIEDADE BRASILEIRA DE ZOOTECNIA, 35., 1998, Botucatu. Anais... Botucatu: Sociedade Brasileira de Zootecnia, 1998. p.189-191.

MACARI, M.; MAIORKA, A. Função gastrinestinal e seu impacto no rendimento avícola. In: CONFERÊNCIA APINCO DE CIÊNCIA E TECNOLOGIA AVÍCOLAS, 2000, São Paulo, 2000. Anais... Campinas: Fundação Apinco de Ciência e Tecnologia Avícolas, 2000. p.51-57, p.161-174.

MERCK. Manual de veterinária: diagnóstico, tratamento, prevenção e controle de doenças para o veterinário. São Paulo: Roca, 1991. p.646.

NITSAN, Z.; DUNNUNGTON, E.; SIEGEL, P. Organ growth and digestive enzyme level to 15 days of age in lines of chickens differing in body weight. Poultry Science, v.70, p.2040-2048, 1991.

ROSTAGNO, H.S.; ALBINO, L.F.T.; DONZELE, J.L. et al. Tabelas brasileiras para aves e suínos. Composição de alimentos e exigências nutricionais. Viçosa, MG: Universidade Federal de Viçosa, 2000. 141p.

SILVA, E.N. Antibióticos intestinais naturais: bacteriocinas. In: SIMPÓSIO SOBRE ADITIVOS ALTERNATIVOS NA NUTRIÇÃO ANIMAL, 2000, Campinas. Anais... Campinas: Colégio Brasileiro de Nutrição Animal, 2000. p.15-24.

UNIVESIDADE FEDERAL DE VIÇOSA - UFV. Sistema de Análise Estatísticas e Genéticas-SAEG. Viçosa, MG: 1992 (Versão 5.0).

ZUANON, J.A.S. Efeito de promotores de crescimento sobre o desempenho de frangos de corte. Viçosa, MG: Universidade Federal de Viçosa, 1995. 70p. Dissertação (Mestrado em Zootecnia) - Universidade Federal de Viçosa, 1995.

Recebido em: 05/02/03 Aceito em: 16/12/03 